\title{
Streptococcus ursoris sp. nov., isolated from the oral cavities of bears
}

\author{
Noriko Shinozaki-Kuwahara, Kazuko Takada and Masatomo Hirasawa \\ Department of Microbiology and Immunology, Nihon University School of Dentistry at Matsudo, \\ Matsudo, Chiba 271-8587, Japan
}

Correspondence

Kazuko Takada

takada.kazuko@nihon-u.ac.jp

\begin{abstract}
Three Gram-positive, catalase-negative, coccus-shaped organisms were isolated from the oral cavities of bears. The isolates were tentatively identified as a streptococcal species based on the results of biochemical tests. Comparative 16S rRNA gene sequencing studies confirmed that the organisms were members of the genus Streptococcus, but they did not correspond to any recognized species of the genus. The nearest phylogenetic relative of the new isolates was Streptococcus ratti ATCC $19645^{\top}$ (98.6\%), however, DNA-DNA hybridization analysis showed that the isolates displayed less than $15 \%$ DNA-DNA relatedness with the type strain of $S$. ratti. Colonies of the novel strains grown on mitis salivarius agar showed an extracellular polysaccharide-producing colony morphology. Based on phenotypic and phylogenetic evidence, it is proposed that the novel isolates are classified in the genus Streptococcus as Streptococcus ursoris sp. nov. The type strain of $S$. ursoris is NUM $1615^{\top}\left(=\mathrm{JCM} 16316^{\top}=\mathrm{DSM} 22768^{\top}\right)$.
\end{abstract}

The genus Streptococcus embraces a broad range of Grampositive, facultatively anaerobic, catalase-negative, chainforming and coccus-shaped organisms. A large number of streptococcal species colonize the oral cavities of animals and humans and these oral streptococci have been divided into five major groups (Facklam, 2002). Among oral streptococci, the mutans group is responsible for dental caries (Hamada \& Slade, 1980). These bacteria are known to form characteristic colonies on mitis salivarius (MS) agar plates demonstrating extracellular polysaccharide synthesis. In humans, it is proposed that water-insoluble glucan, which is synthesized by the action of glucosyltransferase (GTF) from sucrose as the substrate, is one of the most important cariogenic factors (Hamada \& Slade, 1980). Several kinds of mutans streptococcal species, which can synthesize glucans, have been isolated from the oral cavities of various animals, for example, hamster, rat, monkey, pig, bat and wild boar (Beighton et al., 1981; Whiley \& Beighton, 1998; Takada \& Hirasawa, 2007, 2008, 2010). Bears are known to be omnivorous animals and may have the chance to ingest sucrose in the form of sweet fruits, such as berries, and in honey. Dental caries have been reported in the oral cavities of wild bears (Manville, 1990). In this study, three previously unidentified strains isolated from the oral cavity of Japanese black bears (Ursus

Abbreviations: GTF, glucosyltransferase; MS, mitis salivarius.

The GenBank/EMBL/DDBJ accession numbers for the $16 \mathrm{~S}$ rRNA and groEL gene sequences of strain NUM $1615^{\top}$ are AB501126 and AB541991, respectively.

Supplementary figures and a supplementary table are available with the online version of this paper. thibetanus japonicus) and capable of glucan synthesis on MS agar were characterized.

Examination of the oral microflora of bears was performed on MS agar (BD Difco). MS agar is widely used to isolate strains of Streptococcus mutans as well as other oral streptococcal species. Three streptococci-like strains (NUM 1610, NUM $1615^{\mathrm{T}}$ and NUM 1619) obtained from samples from the oral cavities of wild bears were isolated on MS agar. The isolated strains formed small, raised, adherent colonies with irregular margins. The cocci stained as Gram-positive. The strains were grown on brain heart infusion (BHI, BD Difco) agar supplemented with $5 \%$ horse blood at $37{ }^{\circ} \mathrm{C}$ under an atmosphere of $95 \% \mathrm{~N}_{2}$ and $5 \% \mathrm{CO}_{2}$ with non-haemolytic activity. Catalase activity was found to be negative. The organisms were characterized biochemically using the Rapid ID32 Strep, API $50 \mathrm{CH}$ and API ZYM systems according to the manufacturer's instructions (bioMérieux). The colony formation resembled that of members of the mutans streptococcus group, although the biochemical characteristics did not correspond to any recognized species of the genus Streptococcus. The new isolates were subjected to further genetic studies.

Serological analyses of isolates were conducted by agar-gel immunodiffusion methods using rabbit antisera raised against reference strains of mutans streptococci prepared previously (Hirasawa et al., 1980; Takada et al., 1984). Rantz-Randall extract antigens were prepared from cells cultured overnight on BHI as described previously (Rantz \& Randall, 1955). Immunodiffusion experiments with isolate NUM $1615^{\mathrm{T}}$ showed that no cross-reacted precipitin bands formed with any sera prepared against mutans 
Table 1. Characteristics that differentiate strain NUM $1615^{\top}$ from closely related streptococcal species

Taxa: 1, NUM $1615^{\mathrm{T}}$; 2, S. ratti ATCC $19645^{\mathrm{T}}$; 3, S. devriesei CCUG $47155^{\mathrm{T}}$; 4, S. mutans NCTC $10449^{\mathrm{T}}$; 5, S. ferus ATCC 33477 ; 6, S. macacae NCTC $11558^{\mathrm{T}}$. Data for taxa 2, 4, 5 and 6 are from Whiley \& Beighton (1998). Data for taxon 3 are from Collins et al. (2004) and the present study. All taxa give a positive reaction in the Voges-Proskauer test and are positive in tests for the hydrolysis of aesculin and the fermentation of mannitol and sorbitol. +, Positive; -, negative; ND; not detected.

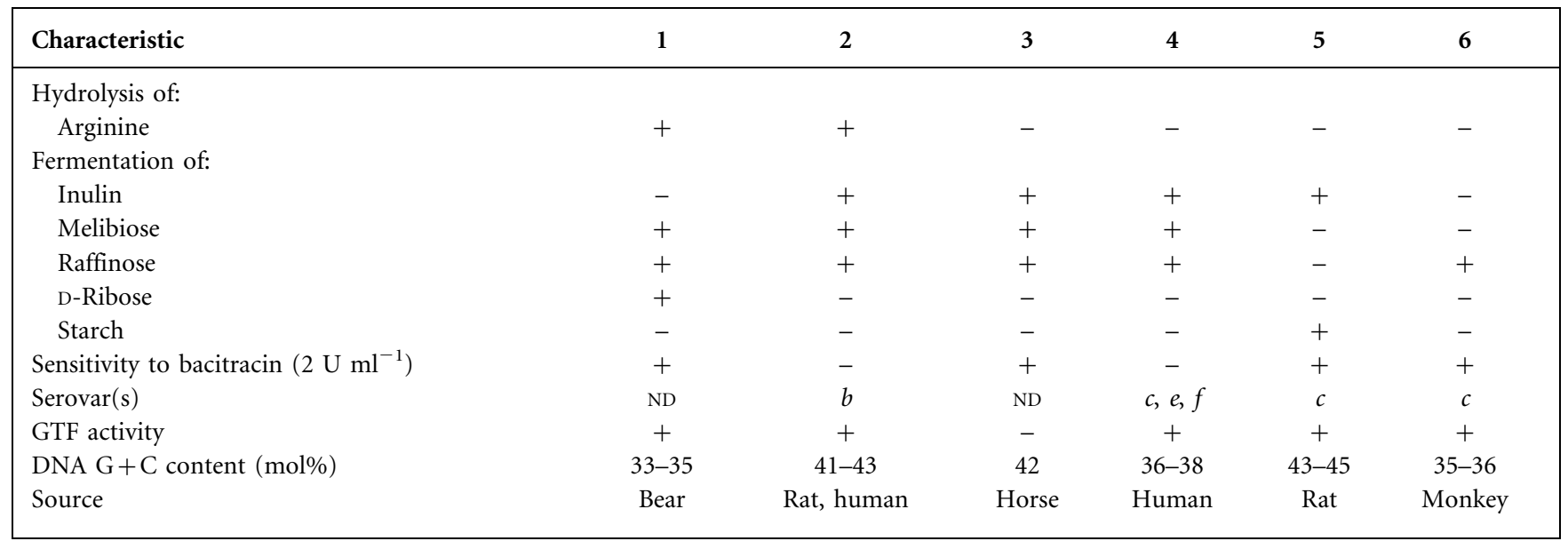

streptococci strains of serotypes $a$ to $h$, suggesting that strain NUM $1615^{\mathrm{T}}$ could not be grouped with any known serotype of mutans streptococci. The Lancefield grouping test was performed using the Streptococcal grouping kit (Oxoid). No Lancefield carbohydrate antigens were detected from strain NUM $1615^{\mathrm{T}}$. Strain NUM $1615^{\mathrm{T}}$ was able to synthesize adhesive water-insoluble glucan from sucrose as the substrate and showed sucrosedependent colonization by the action of GTF enzymes. The phenotypic characteristics that differentiated the new strains from closely related streptococcal species are shown in Table 1.

To determine the $\mathrm{G}+\mathrm{C}$ contents, DNA-DNA relatedness and $16 \mathrm{~S}$ rRNA gene sequences of the isolated strains, chromosomal DNA was extracted and purified as described previously (Shiroza et al., 1998). Measurement of the G +C content of the DNA was carried out by HPLC according to the method of Hirasawa \& Takada (1994). The G+C contents of the three strains ranged from 33 to $35 \mathrm{~mol} \%$ and were similar to those previously determined for Streptococcus macacae and S. mutans. To assess the phylogenetic position of the newly isolated strains, their $16 \mathrm{~S}$ rRNA genes were amplified by PCR using primers described previously by Takada \& Hirasawa (2007), directly sequenced with an ABI PRISM 3130 Genetic Analyzer using a Big Dye Terminator v1.1 Cycle Sequencing kit (Life Technologies Co.) and then subjected to a comparative analysis. The closest known relatives of the new isolates were determined by performing DDBJ/EMBL/ GenBank database searches. The 16S rRNA gene sequences were compared using BLAST algorithms. Distance matrices were determined following the assumptions described by Kimura (1980). Phylogenetic trees were constructed according to the neighbour-joining method (Saitou \& Nei, 1987) and the topology of the tree was estimated by bootstrap analysis using the CLUSTAL $\mathrm{W}$ program (Thompson et al., 1994). Highest sequence similarities were obtained with Streptococcus ratti ATCC $19645^{\mathrm{T}}$ $(98.6 \%)$. The next most closely related strains were Streptococcus devriesei CCUG $47155^{\mathrm{T}}(96.0 \%)$ and $S$. mutans NCTC $10449^{\mathrm{T}}(95.1 \%)$, both of which were below the $97 \%$ threshold value for the definition of separate species. The phylogenetic tree constructed by the

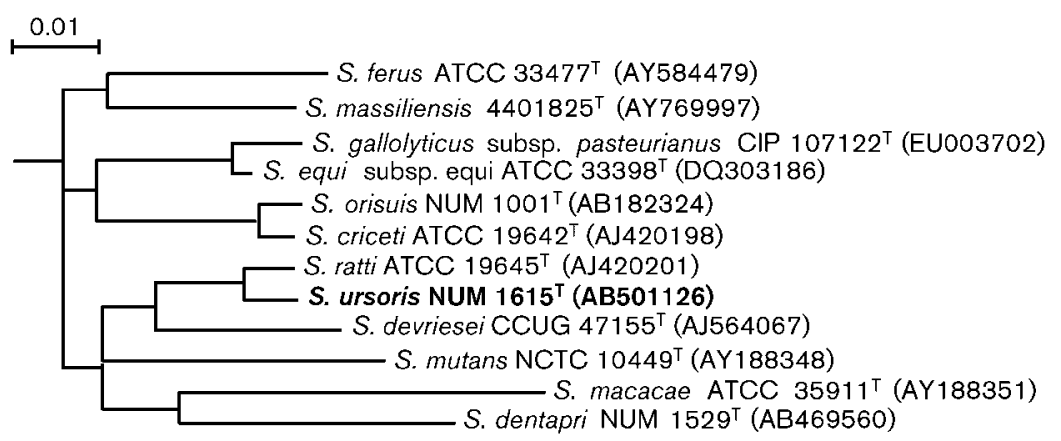

Fig. 1. Phylogenetic tree of members of the genus Streptococcus inferred from comparison of $16 \mathrm{~S}$ rRNA gene sequences by the neighbour-joining method. Bar, 0.01 substitutions per nucleotide position. An extended version of this tree is available as Supplementary Fig. S1. 
neighbour-joining method (Fig. 1; an extended version of this tree is available as Supplementary Fig. S1 in IJSEM Online) revealed a clear affiliation between strain NUM
$1615^{\mathrm{T}}$ and the genus Streptococcus. The phylogenetic trees constructed by the neighbour-joining and maximumparsimony methods (see Supplementary Fig. S2 in IJSEM

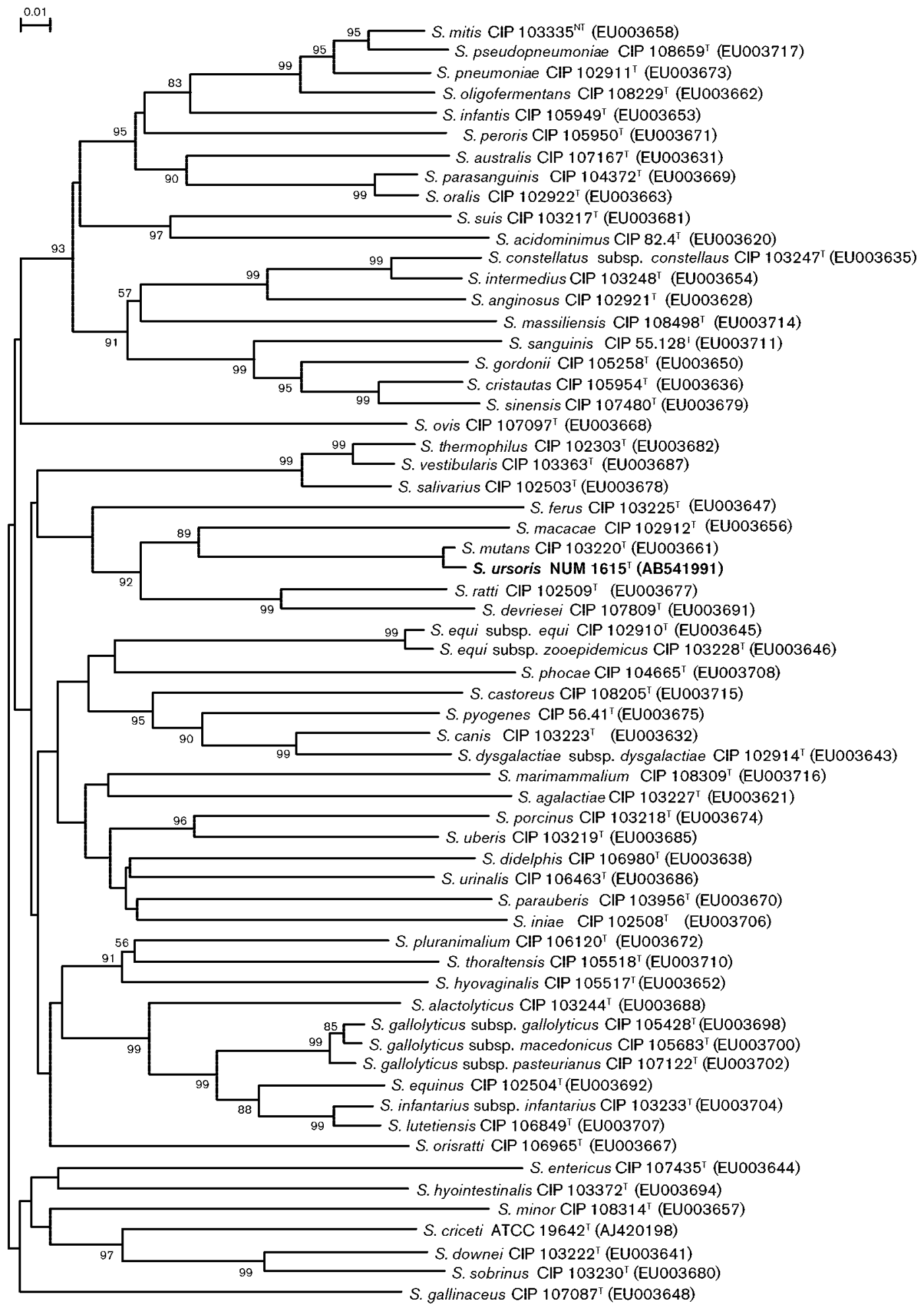

Fig. 2. Phylogenetic tree based on 757 bp of groEL gene fragment sequences constructed by using the neighbour-joining method. Bootstrap values $>50 \%$ calculated for 1000 subsets are shown at branch-points. Bar, 0.01 substitutions per nucleotide position. 
Online) showed a similar evolutionary process for strain NUM $1615^{\mathrm{T}}$ and S. ratti ATCC $19645^{\mathrm{T}}$. A phylogenetic tree (Fig. 2) constructed by the neighbour-joining method with partial sequences of the groEL (757 bp) gene (Glazunova et al., 2009) also confirmed the phylogenetic placement of representative strains within the genus Streptococcus.

DNA-DNA hybridization experiments were performed as previously described (Takada \& Hirasawa, 2007). DNADNA relatedness was examined by labelled DNA from strain NUM $1615^{\mathrm{T}}$ with unlabelled single-stranded DNA from related streptococci (see Supplementary Table S1 in IJSEM Online). The three new isolates showed DNA-DNA relatedness values of $>70 \%$ with each other and therefore these results confirmed that the isolates belonged to the same species (Johnson, 1973). Since the three isolates exhibited high degrees of relatedness, their relationship at the strain level was confirmed. S. ratti ATCC $19645^{\mathrm{T}}$ showed a high $16 \mathrm{~S}$ rRNA gene sequence similarity to strain NUM $1615^{\mathrm{T}}$, but the DNA-DNA relatedness value between the two strains was only $13.3 \%$. The DNA from other streptococci, such as $S$. devriesei and S. mutans, showed low levels of DNA-DNA relatedness to strain NUM $1615^{\mathrm{T}}$ (all $<32 \%$ ).

Therefore, based on phenotypic and phylogenetic criteria, it is considered that strains NUM $1615^{\mathrm{T}}$, NUM 1610 and NUM 1619, isolated from wild bears, warrant classification as a novel species of the genus Streptococcus, for which the name Streptococcus ursoris sp. nov. is proposed.

\section{Description of Streptococcus ursoris sp. nov.}

Streptococcus ursoris (urs.o'ris. L. n. ursus - $i$ bear; L. n. os oris mouth; N.L. gen. n. ursoris of the mouth of a bear).

Cells stain Gram-positive, are non-spore-forming cocci, $0.5-0.7 \mu \mathrm{m}$ in diameter and occur in pairs or short chains. Colonies are white, non-haemolytic and $0.75-1.0 \mathrm{~mm}$ in diameter after incubation on blood agar at $37^{\circ} \mathrm{C}$ for $24 \mathrm{~h}$. On MS agar, colonies appear small, dark blue and crinkled. Facultatively anaerobic and catalase-negative. Lancefield carbohydrate antigens are not detected. Acid is produced from D-glucose, D-fructose, D-galactose, D-mannose, mannitol, sorbitol, $\mathrm{N}$-acetylglucosamine, salicin, cellobiose, maltose, lactose, sucrose, trehalose, raffinose, D-tagatose D-ribose and melibiose, but not from D-arabinose, Dxylose, glycogen, inulin or starch. Aesculin is hydrolysed, but hippurate is not. Voges-Proskauer test is positive. Enzyme activities are detected for arginine dihydrolase, alanyl-phenylalanyl-proline arylamidase, $\beta$-glucosidase, $\alpha$ glucosidase, $\alpha$-galactosidase, naphthol-AS-BI-phosphohydrolase, acid phosphatase, valine arylamidase, cystine arylamidase and leucine arylamidase. $\beta$-Galactosidase, $\beta$ glucuronidase, alkaline phosphatase, $N$-acetyl- $\beta$-glucosaminidase and urease are not produced. Sensitive to bacitracin. In BHI broth, there is no apparent growth at $45{ }^{\circ} \mathrm{C}$ and the GTF enzyme is produced.

The type strain, NUM $1615^{\mathrm{T}} \quad\left(=\mathrm{JCM} \quad 16316^{\mathrm{T}}=\mathrm{DSM}\right.$ $\left.22768^{\mathrm{T}}\right)$, was isolated from clinical specimens obtained from the oral cavity of a bear. The DNA G $+\mathrm{C}$ content of the type strain is $34 \mathrm{~mol} \%$.

\section{Acknowledgements}

We are grateful to Dr Hans Trüper for suggesting the species name. This study was supported in part by a Grant-in-Aid for Young Scientists and a Grant-in-Aid for SBFSR (2008-2012) from MEXT.

\section{References}

Beighton, D., Russell, R. R. B. \& Hayday, H. (1981). The isolation and characterization of Streptococcus mutans serotype $h$ from dental plaque of monkeys (Macaca fascicularis). J Gen Microbiol 124, 271279.

Collins, M. D., Lundstrom, T., Welinder-Olsson, C., Hansson, I., Wattle, O., Hudson, R. A. \& Falsen, E. (2004). Streptococcus devriesei sp. nov., from equine teeth. Syst Appl Microbiol 27, 146-150.

Facklam, R. (2002). What happened to the Streptococci: overview of taxonomic and nomenclature changes. Clin Microbiol Rev 15, 613630.

Glazunova, O. O., Raoult, D. \& Roux, V. (2009). Partial sequence comparison of the $r p o B$, sodA, groEL and gyrB genes within the genus Streptococcus. Int J Syst Evol Microbiol 59, 2317-2322.

Hamada, S. \& Slade, H. D. (1980). Biology, immunology, and cariogenicity of Streptococcus mutans. Microbiol Rev 44, 331-384.

Hirasawa, M. \& Takada, K. (1994). Porphyromonas gingivicanis sp. nov. and Porphyromonas crevioricanis sp. nov., isolated from beagles. Int J Syst Bacteriol 44, 637-640.

Hirasawa, M., Kiyono, H., Shiota, T., Michalek, S. M. \& McGhee, J. R. (1980). Virulence of Streptococcus mutans immunochemical characterization of a serotype- $g$-defective mutant (C307). Infect Immun 27, 697-699.

Johnson, J. L. (1973). Use of nucleic-acid homologies in the taxonomy of anaerobic bacteria. Int J Syst Bacteriol 23, 308-319.

Kimura, M. (1980). A simple method for estimating evolutionary rates of base substitutions through comparative studies of nucleotide sequences. J Mol Evol 16, 111-120.

Manville, A. M., II (1990). Variability of dental diseases in two populations of Great Lakes black bears. In A Selection of papers from the 8th International Conference on Bear Research and Management, Victoria, British Columbia, Canada, February 1989, pp. 129-134. USA: International Association of Bear Research and Management.

Rantz, L. A. \& Randall, E. (1955). Use of autoclaved extracts of hemolytic streptococci for serological grouping. Stanford Med Bull 13, 290-291.

Saitou, N. \& Nei, M. (1987). The neighbor-joining method: a new method for reconstructing phylogenetic trees. Mol Biol Evol 4, 406425.

Shiroza, T., Shinozaki, N., Watanabe, T., Ikemi, T., Fukushima, K. \& Abiko, Y. (1998). Rapid isolation of chromosomal DNA from oral streptococci and polymerase chain reaction-oriented restriction fragment-length polymorphism. Oral Microbiol Immunol 13, 1116.

Takada, K. \& Hirasawa, M. (2007). Streptococcus orisuis sp. nov., isolated from pig oral cavity. Int J Syst Evol Microbiol 57, 12721275.

Takada, K. \& Hirasawa, M. (2008). Streptococcus dentirousetti sp. nov., isolated from the oral cavities of bats. Int J Syst Evol Microbiol 58, 160-163. 
Takada, K. \& Hirasawa, M. (2010). Streptococcus dentapri sp. nov., isolated from the wild boar oral cavity. Int J Syst Evol Microbiol 60, 820-823.

Takada, K., Wyszomirska, J. \& Shiota, T. (1984). Serological characterization of Streptococcus mutans serotype polysaccharide $g$ and its different molecular weight forms. Infect Immun 45, 464-469.
Thompson, J. D., Higgins, D. G. \& Gibson, T. J. (1994). CLUSTAL W: improving the sensitivity of progressive multiple sequence alignment through sequence weighting, position-specific gap penalties and weight matrix choice. Nucleic Acids Res 22, 4673-4680.

Whiley, R. A. \& Beighton, D. (1998). Current classification of the oral streptococci. Oral Microbiol Immunol 13, 195-216. 